ЗАЛИВАНСКИЙ Борис Васильевич - кандидат социологических наук, доцент кафедры социальных технологий и государственной службы Белгородского государственного национального исследовательского университета (308015, Россия, г. Белгород, ул. Победы, 85; zalivansky@bsu.edu.ru) САМОХВАЛОВА Елена Владиславовна - кандидат социологических наук, доцент кафедры социальных технологий и государственной службы Белгородского государственного национального исследовательского университета (308015, Россия, г. Белгород, ул. Победы, 85; samokhvalova @bsu. edu.ru)

ПОЛУХИН Олег Николаевич - доктор политических наук, профессор; ректор Белгородского государственного национального исследовательского университета (308015, Россия, г. Белгород, ул. Победы, 85;; pоп@bsu.edu.ru)

\title{
ВОСПРИЯТИЕ МАСШТАБОВ РАСПРОСТРАНЕНИЯ КОРРУПЦИИ РЕГИОНАЛЬНЫМ СООБЩЕСТВОМ
}

\begin{abstract}
Аннотация. В статье исследуется проявление коррупционных практик в системе государственной и муниципальной власти. С целью выявления фактических значений параметров оценки коррупции проанализированы результаты социологического опроса 623 жителей Белгородской обл., проживающих в 16 населенных пунктах. С использованием метода качественно-количественной интерпретации эмпирических данных определены масштабы и структура коррупции, выявлены факторы, обусловливающие характер и содержание коррупционных практик в регионе. Авторы приходят к выводу, что основным триггером коррупционных процессов является несформированность антикоррупционных установок и моделей поведения у большинства представителей регионального сообщества. В заключении даны рекомендации, которые могут способствовать минимизации коррупционных практик и повышению уровня антикоррупционной культуры населения.
\end{abstract}

Ключевые слова: коррупция, население региона, социологический опрос, органы государственной и муниципальной власти

Введение. Распространение коррупционных практик наносит колоссальный ущерб экономическому развитию и политической репутации большинства стран мира, в т.ч. России [Березюк, Яремчук 2020; Нисневич 2020; Zakharov 2019]. В этой связи важнейшей государственной задачей становится преодоление коррупции.

В то же время современная антикоррупционная политика России все еще недостаточно эффективна. Отчасти этому способствует отсутствие объективного представления о ней [Olken 2009; Ryvkin, Serra, Tremewan 2017]. Современные исследователи сходятся во мнении, что теневой характер коррупционных сделок не позволяет оценивать масштабы распространения коррупции с помощью объективных показателей, например числа выявленных преступлений коррупционной направленности или среднего размера коррупционной сделки в той или иной сфере. Кроме того, интерпретация этих показателей и их динамики существенно затруднена ввиду отсутствия общепризнанных на мировом уровне подходов и методик оценки [Lee, Liu 2021].

Отчасти выходом из сложившейся ситуации может стать дополнение объективных данных значениями показателей субъективного восприятия населением масштабов распространения коррупции на территории их проживания. В то же время следует согласиться с мнением современных авторов, что измерение представлений о коррупции тоже лишь элемент механизма оценки, который позволяет избежать трудностей, присущих процедуре измерения, но 
поднимает вопрос, как опрошенные формируют свое восприятие и насколько точны эти представления на самом деле [Olken 2009; Budsaratragoon, Jitmaneeroj 2020].

Следует учитывать, что субъективное восприятие населением действий органов власти, в т.ч. по противодействию коррупции, формируется не только с учетом личного коррупционного опыта [Bertrand, Mullainathan 2001], но и под воздействием средств массовой информации, транслирующих соответствующий контент в интернет-среде [Goel, Nelson, Naretta 2012]. При этом рост числа публикаций о новых случаях коррупции не только негативно коррелирует с восприятием населением масштабов ее распространения, но и приводит к дальнейшему воспроизводству коррупционных практик в ситуации, когда коррупция становится неформальной нормой. Тяжелым последствием распространения подобных представлений является снижение доверия населения к публичным институтам [Shlapentokh 2006; Solé-Ollé, Sorribas-Navarro 2018].

В этой связи органы власти как никто другой заинтересованы в оценке коррупционной ситуации и информировании о ее результатах жителей собственных территорий.

Методология. Настоящее исследование было проведено в Белгородской области в 2020 г. при участии авторов в соответствии с методикой оценки уровня коррупции в субъектах РФ, утвержденной постановлением Правительства РФ от 25 мая 2019 г. № 662 (далее - Методика).

Число репрезентативных единиц отбора в настоящем исследовании составляет 623 респондента, проживающих в столице Белгородской обл., городах областного значения, городах и поселках городского типа районного значения, сельских населенных пунктах. Доли городских и сельских жителей к общей численности населения в возрасте от 18 лет в отобранных для опроса административно-территориальных единицах составляют $67,33 \%$ и $32,67 \%$, что весьма близко к общеобластному значению.

В соответствии с половозрастной структурой населения области в выборочной совокупности преобладают женщины (55,5\% против 44,5\% опрошенных мужчин). Почти каждый четвертый респондент $(25,2 \%)$ - белгородец в возрасте старше 60 лет, а почти каждый пятый $(19,9 \%)$ относится к возрастной группе от 31 до 40 лет. Доля опрошенных жителей области в возрасте от 21 до 30 лет, как и белгородцев «предпенсионного» возраста (от 51 до 60 лет), составила $17,7 \%$ общего числа опрошенных. Самая малочисленная группа респондентов - молодые люди в возрасте от 18 до 20 лет (4,2\%).

Результаты. Анализ результатов настоящего исследования частично подтверждает мнение современных исследователей, что в России коррупция, несмотря на формальный запрет, давно стала неформальной нормой, а участие в подобных отношениях - социально одобряемым поведением. 38,0\% участников настоящего исследования не осуждают ни тех, кто дает, ни тех, кто берет взятки. Мнения остальных участников разделились: 14,8\% осуждают тех, кто берет, всего 2,9\% осуждают тех, кто дает, и 34,8\% осуждают обе стороны коррупционной сделки. Почти каждый десятый затруднился с ответом на данный вопрос.

Рассуждая о причинах возникновения коррупционных ситуаций, 45,6\% респондентов подтверждают, что инициатива дачи взятки часто принадлежит самим заявителям. Иными словами, население одобряет такой вид взаимодействия, успокаивая себя, что так спокойнее, надежнее. Еще почти трети опрошенных белгородцев $(29,2 \%)$ известно из личного опыта и от ближайшего окружения, что без взятки не обойтись, вследствие чего они и не стремятся 
нарушать установленный со слов родных, знакомых порядок взаимодействия с должностными лицами. В свою очередь, только $25,2 \%$ жителей области выразили мнение, что коррупционные ситуации возникают по инициативе чиновников (должностных лиц), когда они дают понять, что именно так следует сделать, заставляют давать взятки.

Очевидно, что для жителей области характерно наличие двойных стандартов; в гораздо большей степени негативно они относятся к тем, кто берет, но при этом склонны сами «отблагодарить» чиновника (должностное лицо) даже в ситуации, когда у них взятку никто не вымогает.

Жителю Белгородской обл., попавшему в коррупционную ситуацию и согласившемуся на дачу взятки, придется потратить на нее на $20 \%$ больше суммы среднегодового месячного подушевого дохода ${ }^{1}$, т.к. величина среднего размера взятки в сфере «бытовой» коррупции, рассчитанного по Методике согласно ответам респондентов, составляет 39590 руб.

$85,89 \%$ опрошенных белгородцев смогли назвать причину, по которой точно не стали бы участвовать в коррупционных отношениях. Самая весомая из них - наличие личных антикоррупционных ценностей и установок. Так, 23,93\% заявили, что принципиально не дают взяток, даже если все это делают. Чуть более «мягкую» позицию заняли $15,34 \%$ жителей области, указав, что им противно это делать. Следующими по популярности являются ответы «могу добиться своего и без взяток, другим путем» $(17,79 \%)$ и «для меня это слишком дорого» $(14,11 \%)$.

Неизбежность наказания пугает только 6,13\% жителей области, вероятно, латентный характер коррупционных преступлений формирует у граждан представление о ничтожно малой вероятности наказания за подобные деяния. Среди вариантов, отнесенных к категории «другое», есть такие мнения, что чиновники «должны выполнять обязанности без взяток», «это незаконно» и «не жалко дать только отдельным категориям, например врачу».

В ходе исследования белгородцам было предложено оценить, как часто в их городе (поселке, селе) таким людям, как они, приходится сталкиваться со взяточничеством, коррупцией в различных ситуациях (обстоятельствах) их взаимодействия с представителями органов власти.

Топ-5 наиболее коррупциогенных ситуаций (обстоятельств) выглядит следующим образом 2 : получение бесплатной медицинской помощи $(45,1 \%$ респондентов считают, что белгородцам приходится с различной частотой сталкиваться в этом случае с коррупцией); обучение в вузе (поступить, перевестись из одного вуза в другой, экзамены и зачеты, диплом и др.) - 32,1\%; поступить в нужную школу и успешно ее окончить, обучение, «взносы», «благодарности» и др. - 29,8\%; урегулирование ситуации с автоинспекцией (получение прав, техосмотр, нарушение правил и др.) - 27,1\%; получение работы, обеспечение продвижения по службе - 26,5\%.

Подчеркнем, при ответе на данный вопрос жители транслировали устоявшееся в обществе восприятие безотносительно к личному опыту, а изучение масштабов распространения коррупции в каждой конкретной сфере требует отдельного, более детального изучения. В то же время сравнительно чаще других коррумпированными представляются наиболее массовые, наименее регламентированные и предполагающие личный контакт с потребителями услуги -

\footnotetext{
1 Величина среднегодового месячного подушевого дохода в Белгородской обл. в 2020 г. составляла 32624 руб.

2 При анализе в данном случае учитывалась сумма ответов «редко», «время от времени», «довольно часто», «очень часто».
} 
получение медицинской помощи, обучение в вузе, школе, ДОУ, получение работы.

Еще одной коррумпированной, по мнению населения, сферой традиционно остается жилищно-коммунальное хозяйство. Практически каждый пятый участник опроса $(21,6 \%)$ уверен, что при получении услуг по ремонту, эксплуатации жилья придется столкнуться с коррупцией.

Отдельно следует отметить и сформированный в сознании жителей области негативный образ правоохранительных органов и судебных инстанций - представителей государства, призванных бороться с коррупцией. 27,6\% респондентов заявили, что придется столкнуться с коррупцией при урегулировании ситуации с автоинспекцией, $22,8 \%$ - при обращении за помощью и защитой в полицию, 20,3\% - при обращении в суд.

$54,8 \%$ опрошенных белгородцев оказались в той или иной степени информированными о политике по противодействию коррупции, реализуемой представителями власти разных уровней. Из них 14,1\% активно интересуются подобной информацией, следят за ходом антикоррупционных мероприятий, 20,2\% что-то знают, но специально за этим не следят, и еще 20,5\% что-то слышали, но ничего определенного припомнить не могут.

Одновременно достаточно большая доля жителей области $(42,4 \%)$ практически ничего не знает об антикоррупционных мерах, реализуемых на государственном и муниципальном уровнях. Это укладывается в картину слабой информированности населения о деятельности органов власти, сформировавшуюся не только по причине недостаточной открытости последней, но и из-за слабой заинтересованности населения в информации подобного рода. Еще 2,7\% респондентов затруднились ответить на поставленный вопрос.

Респондентам, информированным о мерах по противодействию коррупции, было предложено оценить усилия власти, прилагаемые в этом направлении. В итоге выяснилось, что нацеленность власти на противодействие коррупции у большинства жителей области вызывает сомнение. Так, вариант ответа «делают все возможное» был выбран только в 9,5\% случаев, а близкий к нему по смыслу «делают многое» - только в 6,6\%. Напротив, «делают мало» и «ничего не делают» - самые популярные варианты у респондентов, они набрали 39,0\% и $31,1 \%$ голосов соответственно. Затруднились оценить действия власти или ничего не ответили на вопрос в совокупности $11,2 \%$.

Таким образом, население региона все еще недостаточно информировано о намерениях власти победить коррупцию и о результатах проводимой антикоррупционной работы.

Заключение. Проявлениям коррупции в российском регионе способствует несовершенство административных процессов. Несмотря на прилагаемые в Белгородской обл. усилия по повышению эффективности предоставления государственных (муниципальных) услуг, потребителей все еще недостаточно устраивает их качество и доступность. В итоге они либо сами выступают инициаторами коррупционных отношений, потому что так надежнее, либо молчаливо следуют неформально установленному порядку взаимодействия с должностными лицами в надежде получить 100-процентный результат. В этой связи необходимо вести работу по дальнейшей регламентации и «оцифровке» административных процедур с точки зрения их оптимальности для потребителей; полному переводу общественно значимых услуг в электронную форму; обеспечению максимального информирования потребителей, получению от них обратной связи и адекватной управленческой реакции на нее.

Фактором, стимулирующим распространение «бытовой» коррупции, является несформированность антикоррупционных установок и моделей поведе- 
ния у населения. В этой связи необходимо более активно вести образовательную и воспитательную работу среди молодежи и информационно-просветительскую - среди взрослых белгородцев.

Образ чиновника-коррупционера, как и распространенное представление «воруют все», сформировано скорее с участием СМИ, публикующих разоблачающие материалы, создающих дополнительный благоприятный фон для распространения коррупции. В этой связи следует вести работу по целенаправленному формированию имиджа честного чиновника, работать над информированностью населения о деятельности власти, повышать открытость, прозрачность деятельности государственных (муниципальных) учреждений.

\section{Список литературы}

Березюк С.В., Яремчук Н.В. 2020. Коррупция как деструктивный фактор экономического развития. - The Scientist Heritage. № 47-6. С. 11-21.

Нисневич Ю.А. 2020. Политика и коррупция: коррупция как фактор мирового политического процесса. М.: Юрайт. 240 с.

Bertrand M., Mullainathan S. 2001. Do People Mean what They Say? Implications for Subjective Survey Data. - American Economic Review. Vol. 91. P. 67-72.

Budsaratragoon P., Jitmaneeroj B. 2020. A Critique on the Corruption Perceptions Index: An Interdisciplinary Approach. - Socio-Economic Planning Sciences. Vol. 70(C). URL: http://www.sciencedirect.com/science/article/pii/S0038012118301411 (accessed 16.11.2021).

Goel R., Nelson M., Naretta M. 2012. The Internet as an Indicator of Corruption Awareness. - European Journal of Political Economy. Vol. 28. Is. 1. P. 64-75.

Jekyung Lee, Cheol Liu 2021. Public Corruption and Government Management Capacity. - Public Performance \& Management Review. URL: https://doi.org/10.1080 /15309576.2021.1985538 (accessed 16.11.2021).

Olken B. 2009. Corruption Perceptions vs Corruption Reality. - Journal of Public Economics. Vol. 93. Is. 7-8. P. 950-964.

Ryvkin D., Serra D., Tremewan J. 2017. I Paid a Bribe: An Experiment on Information Sharing and Extortionary Corruption. - European Economic Review. Vol. 94 (C). P. 1-22.

Shlapentokh V. 2006. Trust in Public Institutions in Russia: The Lowest in the World.

- Communist and Post-Communist Studies. Vol. 39. Is. 2. P. 153-174.

Solé-Ollé P., Sorribas-Navarro P. 2018. Trust no More? On the Lasting Effects of Corruption Scandals. - European Journal of Political Economy. Vol. 55. P. 185-203.

Zakharov N. 2019. Does Corruption Hinder Investment? Evidence from Russian Regions. - European Journal of Political Economy. Vol. 56 (C). P. 39-61. 
ZALIVANSKIY Boris Vasilevich, Cand.Sci. (Soc.), Associate Professor of the Chair of Social Technologies and Public Administration, Belgorod State National Research University (85 Pobedy St, Belgorod, Russia, 308015; zalivansky@bsu. edu.ru)

SAMOKHVALOVA Elena Vladislavovna, Cand.Sci. (Soc.), Associate Professor of the Chair of Social Technologies and Public Administration, Belgorod State National Research University (85 Pobedy St, Belgorod, Russia, 308015; samokhvalova@bsu.edu.ru)

POLUKHIN Oleg Nikolaevich, Dr.Sci. (Pol.Sci.), Professor; Rector of Belgorod State National Research University (85 Pobedy St, Belgorod, Russia, 308015; pon@bsu.edu.ru)

\title{
PERCEPTION OF THE SCALE OF CORRUPTION BY THE REGIONAL COMMUNITY
}

\begin{abstract}
The article examines the manifestations of corruption practices in the regional government. The results of a sociological survey of 623 residents of the Belgorod Region from the 16 settlements were analyzed in order to identify the actual values of the parameters for assessing corruption. Using the method of qualitative and quantitative interpretation of empirical data, the authors determine the scale and structure of corruption, and identify the factors that determine the nature and content of corruption practices in the region. They show that the main trigger of corruption processes is the lack of formation of anti-corruption attitudes and behavior among the majority of the regional community members. The article contains recommendations that can help minimizing corruption practices and increasing the level of anti-corruption culture of the regional community.
\end{abstract}

Keywords: corruption, regional population, sociological survey, state and municipal authorities 